\title{
Toward a More Caring Code of Engineering Ethics
}

\section{Dr. Elisa Warford, University of Southern California}

Elisa Warford is a senior lecturer in the Engineering Writing Program at the University of Southern California, where she teaches undergraduate and graduate courses in written and oral engineering communication and the ethics of science and technology. Her current research interests include the rhetoric of science and portrayals of engineering and technology in American literature. She is also a professional technical editor specializing in engineering writing for academia and industry. She holds a Ph.D. in English from the University of Maryland. 


\title{
Toward a More Caring Code of Engineering Ethics
}

\begin{abstract}
Despite recent scholarly work that emphasizes the importance of the ethic of care in engineering practice, care ethics are not reflected in most engineering codes of ethics. Rather, the canons of these codes more often reflect traditional "universal" moral principles. Since despite their limitations, the codes of ethics are important aspirational and normative value statements for the profession - and are frequently used to teach engineering ethics - this paper proposes that the codes should include canons that reflect the ethic of care. The paper first summarizes the theory of care ethics as developed by Carol Gilligan and Nel Noddings and addresses critiques of care ethics as they relate to engineering. Next, it applies care virtues to engineering to suggest that care ethics are appropriate values for engineering practice. It proposes that care ethics could be incorporated in canons that are based on virtue ethics and suggests revisions and additions to the NSPE code of ethics that would reflect care ethics. The paper concludes by suggesting that a stronger integration of care ethics into the codes of ethics may foster a more widespread inclusion of care ethics in engineering ethics instruction.
\end{abstract}

\section{Introduction}

Since Carol Gilligan's [1] and Nel Noddings' [2] groundbreaking work in the 1980s that challenged traditional, patriarchal notions of universal moral development and ethical values, care ethics has advanced a field of feminist ethics that has emphasized moral sentiment, interdependent human relationships, and contextuality. Care ethics has been applied to many fields, perhaps most notably in bioethics and medicine, whose explicit aim is to care for others. Care ethics has also been applied to engineering. As early as 1999, Pantazidou and Nair directly connected care ethics to engineering design and pedagogy [3]. Care ethics aligns with scholarship in science and technology studies that recognizes the value-laden nature of technologies, and the concomitant shift in engineering practice to human-centered designdesign that "increasingly places the human impact of design and its products at the center of the deliberations" [4]. By definition, human-centered design requires the engineer to consider the user's needs and interests, and thus care ethics, which is fundamentally "other-directed" [2], has increasingly been seen as important to engineering education and practice. A quick search of ASEE conference proceedings for "care ethics," "ethic of care," or "value of care" from 2007 through 2017 returns 40 papers, and if "empathy" is added (a disposition or virtue related to caring, since caring "requires that we meet the other morally, adopt that person's, or group's, perspective and look at the world in those terms" [5]), the number jumps to 417. As engineering educators, we clearly believe it is important to teach our students to understand and care about the ways their designs affect others and to consider the entire social context in which their designs will be used.

Yet despite scholarly interest in care ethics in engineering education and practice, the values of care are not reflected in engineering codes of ethics. Rather, these codes of ethics tend to reflect values based on traditional "universal" moral principles. Since the codes of ethics are the most 
visible normative value statements in the profession, the absence of the ethic of care in the codes is problematic. Therefore, in this paper, I contend that it would be appropriate and beneficial to engineering practice and education for the codes of ethics to incorporate language that reflects the value of care. In the remainder of the paper, I provide an overview of care ethics, address critiques against care ethics as they relate to engineering, discuss shortcomings of the codes of ethics and how care ethics might overcome these limitations, and propose language that might be used in the NSPE code of ethics to reflect the value of care.

\section{Overview of care ethics}

Care ethics emerged in the 1980s with the publication of two seminal works in feminist ethics, a study by Carol Gilligan [1] based on the psychology of moral development and a treatise by Nel Noddings on the ethic of care [2]. While a body of work in care ethics has grown since the publication of these two seminal works, Gilligan's and Noddings' works are widely acknowledged as the foundation of care ethics, so I briefly summarize them here.

In 1982, Gilligan published In a Different Voice [1], in which she critiqued Lawrence Kohlberg's theory of moral development [6], which posited progression from an "egocentric model," to "a conception of fairness anchored in the shared conventions of societal agreement," to a "principled understanding of fairness that rests on the free-standing logic of equality and reciprocity" [1]. This model favors logic and universal principles of justice, and assumes an atomistic self who limits self-interested actions so that other individuals might also fulfill their self-interested goals. In this model, girls' moral development was typically seen as inferior to boys', as girls often did not progress "up" the scale. Gilligan questioned the validity of Kohlberg's criteria, asserting that girls spoke in different, not inferior, ways about morality. Girls, she found, asked for more information about the context of the situation and hesitated to make moral judgments based on universal principles. These traits, Gilligan argued, were not signs of an inferior moral sensibility, but of a different understanding of morality, one based on relationships and specific situations in "a world comprised of relationships rather than of people standing alone, a world that coheres through human connection rather than through systems of rules" [1]. For men, she found, "the moral imperative appears rather as an injunction to respect the rights of others and thus to protect from interference the rights to life and selffulfillment" [1]. In contrast, for women, Gilligan argued, "the moral imperative that emerges repeatedly...is an injunction to care, a responsibility to discern and alleviate the 'real and recognizable trouble' of this world" [1].

Nel Noddings' Caring: A Feminine Approach to Ethics and Moral Education (1984) similarly questioned ethical theories that privilege rationality and universal moral principles, arguing instead for the primacy of "ethical care," modeled on the mother's caring sentiment for her infant. For Noddings, moral sentiment, rather than rationality, is the basis of ethics. She advocates an ethical ideal of the "one-caring," which emphasizes the importance of the self in relationship with the other: "The virtue described by the ethical ideal of one-caring is built up in relation. It reaches out to the other and grows in response to the other" [2]. She valorizes the 
caring relation as "superior to...other forms of relatedness" [2]. Like Gilligan, she eschews universal principles (other than caring) because they assume that "human predicaments exhibit sufficient sameness," when in reality, a condition "which makes the situation different and thereby induces genuine moral puzzlement cannot be satisfied by the application of principles developed in situations of sameness" [2]. She deemphasizes judgment between right and wrong because for her, these principles cannot be universalized but rather must be determined according to each situation; even then, the one-caring hesitates to judge but rather asks how she can help.

These two works helped advance a field of feminist ethics that locates the basis for ethics in moral sentiment rather than reason; conceives of the self as always in relationship with others, rather than as an atomistic, autonomous individual; and conceives of ethical decisions as dependent on context and particulars rather than universal moral principles.

\section{Critiques of care ethics}

While feminist ethicists have welcomed care ethics' critique of the masculinist assumptions undergirding deontology and utilitarianism, other aspects of care ethics have been criticized. Critics of care ethics have leveled several charges against care ethics: that its empirical basis is flawed [7], [8]; that it reinforces a slave morality in which women's subservience to others is valorized [9] - [11]; that it does not recognize the diversity of women's experiences in terms of class, ethnicity, and sexual orientation [5]; that it is theoretically indistinct from virtue ethics and other ethical theories [12] (which I will return to later); that it does not adequately account for questions of justice; that it is essentialist [5]; and that it is relevant to the private domain but not the public [5]. While it is outside the scope of this paper to mount a full-length defense of care ethics against all these criticisms, here I briefly address the last two, since, if these charges against care ethics are correct, the theory would have limited application to engineering.

\section{Is care ethics essentialist?}

Gilligan's and Noddings' theories seem to posit an essential difference between men and women. Gilligan argues that women have an essentially "different," feminine understanding of morality, and Noddings models her caring relationship on the mother-child relationship (although she points out that "she does not imply a claim to speak for all women nor to exclude men" [2]). Critics have contended that Gilligan's methodology was flawed; later studies have found less difference between girls and boys [8]. Also, because caring duties are typically undervalued in society, and because Gilligan and Noddings primarily associate ethical care with women, critics contend that care ethics reinscribes gender stereotypes that historically have oppressed women. Care ethics, critics say, reinforces and valorizes stereotypical "women's virtues" such as altruism and self-sacrifice, virtues associated with women that have resulted in their oppression and inferior status.

If the caring sentiment is indeed more innate to women, then care ethics can have little application to engineering, which is practiced by both men and women. But others have argued 
that care ethics need not - indeed, should not—-be construed as gender-specific. Margaret McLaren de-links care from women, reclaiming care as a feminist virtue rather than a feminine virtue: as a feminist virtue, she suggests, rather than limiting women's role to self-sacrificial caregiving, care is "essential to helping us envision morally desirable alternatives that promote equality and emancipation" [13]. Joan Tronto and others have argued that everyone participates in caring, since everyone gives and receives care at different times throughout their lives [5].

Regardless of whether women are innately more "caring" than men or are encouraged by society to act so, the profession of engineering might more easily recruit women by better portraying itself as a helping profession. While engineering offers a powerful way to improve people's lives, it is not typically perceived this way by the public. Research suggests that women are attracted to professions that help others [14] or serve communal goals [15]. Thus, the thinking goes, if engineering were more widely seen as a helping or communal profession, more female students may be attracted to it. Indeed, since recruiting women into the field seems to be one aim of recent work in engineering education, and incorporating the ideal of care more explicitly into engineering may align with this goal.

\section{Is care ethics useful only in the private sphere?}

Another charge against care ethics relevant to engineering is that the theory is useful only in the private sphere, not the public sphere. Care, and the moral sentiment that motivates it, this argument goes, is pre-cognitive and thus irrelevant to the public sphere, which requires decisions to be made based on reason and impartiality. If true, this would seem to relegate care ethics to interpersonal relationships, without much to say about relationships in the public, political sphere. In this case, care ethics would have no place in a normative code of ethics for business or public relationships.

In her later work, Noddings herself refutes the idea that care ethics is limited to interpersonal relationships [16]. She theorizes that the model of a caring home and family life can be extended to parts of political life. Such a caring society would actively facilitate caring relationships, in part by rejecting "any principle or rule that makes it impossible for people in responsible positions to respond with care to those who plead for care or obviously need it." The idea, she says, is "to recognize that all of us remain interdependent both economically and morally. We must logically reject the independent-dependent dichotomy" [16] This idea, she says, is "entirely compatible with liberal economics." Similarly, Tronto rejects the boundaries between public and private as they are currently drawn [5], arguing that "all moral arguments have a political context" (emphasis original), and that "care can serve as both a moral value and as a basis for the political achievement of a good society" [5]. She argues that, because care "helps us to rethink humans as interdependent beings," it can "prescribe an ideal for more democratic, more pluralistic politics in the United States, in which power is more evenly distributed" [5]. Since technology shapes and is shaped by power structures and relationships [17], the engineering profession is not a neutral actor here, but rather should concern itself with whether it is making more or less possible a caring, humane society. 
Care ethics is also sometimes faulted for being insufficiently concerned with justice, as it does not demand impartiality on the part of the one-caring and concerns itself with particulars rather than universal principles. It can be interpreted to allow partiality to people's loved ones, limiting our obligations to those outside our caring scope. But several ethicists have argued that care is necessary for a just society. Tronto argues that the problem is not that care without justice is incomplete, but the opposite: that "justice without a notion of care is incomplete" [5]. Noddings suggests that "caring-about supplies an important motive for justice and generates much of its content....When we cannot care directly for others but wish that we could...we rely on principles of justice that approximate...the actions we would perform if we could be bodily present" [16]. Virginia Held [18], and Daniel Engster [19] have also developed theories of economic justice based on principles of care. These efforts accord with work being done on social justice in engineering education by scholars such as Donna Riley [20] and George Catalano [21], who argue that engineering is well suited to address problems in social justice and that engineers have a duty to work to advance it.

The criticism that care ethics is essentialist and parochial raises valid concerns, and it has motivated care ethicists to refine and extend their theories. Thus, despite the perceived flaws of care ethics discussed here, the theory offers an important alternative, or perhaps an added dimension, to traditional ethical theories upon which engineering ethics can be based. With its insistence on contextuality and relationships, its critique of the primacy of reason to determine ethical values, and its directive to consider the other, care ethics can serve as a useful normative theory for political and business relations, and, as I will argue in the next section, for the profession of engineering.

\section{Caring virtues in engineering}

Since Gilligan's and Noddings' early work, ethicists have further developed theories of care in ways that make it appropriate for use in engineering. The practice of care has been defined by Daniel Engster as "everything we do directly to help individuals to meet their vital biological needs, develop or maintain their basic capabilities, and avoid or alleviate unnecessary or unwanted pain and suffering, so that they can survive, develop, and function in society" [20, emphasis original]. Since the purpose of technological development is to meet human needs, some engineering activities can be thought of as caring activities. Engster distinguishes between purely economic activities such as "producing, distributing, and selling goods" and caring practices. Of course, much engineering activity is involved in the production of consumer goods that do not contribute to caring. But technologies are essential to our ability to perform caring activities, such as feeding, sheltering, educating, and caring for the ill. Thus, while engineering may also serve purposes other than caring, its role in caring is crucial. Joan Tronto and Berenice Fisher define care more broadly than Engster, as an activity essential to human survival, "a species activity that includes everything we do to maintain, continue and repair our 'world'so that we can live in it as well as possible. That world includes our bodies, our selves, and our environment" [5, emphasis original]. Tronto argues that caring need not imply a dyadic, one-to- 
one relationship, and that caring activities include caring for objects and for the environment. This maintaining and repairing activity aligns well with many of the aims of engineering practice: engineers' contributions to biomedical technologies, communications technologies, and environmental technologies could be considered forms of care according to Tronto's definition. ${ }^{1}$

Indeed, as discussed in the introduction to this paper, engineering educators have worked to incorporate the value of care in engineering education. But despite engineering educators' interest in promoting the value of care in engineering practice, care is not well reflected in the most fundamental value statements of the profession: the engineering codes of ethics. Martin and Schinzinger [22] emphasize the importance of the codes to the profession:

Because they express the profession's collective commitment to ethics, codes are enormously important, not only in stressing engineers' responsibilities but also in supporting the freedom needed to meet them. Codes of ethics play at least eight essential roles: serving and protecting the public, providing guidance, offering inspiration, establishing shared standards, supporting responsible professionals, contributing to education, deterring wrongdoing, and strengthening a profession's image.

Most, if not all, codes of ethics direct engineers to be dedicated to "the protection of the public health, safety, and welfare," as phrased in the NSPE code of ethics [23], and thus consider others in their practice. This is an improvement over early codes that made no reference to the public [24]. But these types of directives are not necessarily based on caring: they do not require the engineer to care but rather to obey negative duties to not infringe on others' rights to life and health or positive duties to work for the greater good. Normative statements found in the canons such as "do not deceive" and "avoid conflicts of interest" are also based on traditional moral principles. Given the significance of the codes of ethics to the profession, the absence of the value of care from them is problematic.

Troxell and Troxell [25] suggest that the codes operate under rule utilitarianism, in which the best moral choice is that which follows the general moral rule, the rule having been determined to produce the greatest good in most situations. But they find that this rule utilitarianism does not provide guidance for situations in which the codes, or rules, yield conflicting answers: "[I]t remains possible for engineers to encounter concrete situations where two incommensurable moral considerations carry equal weight, where interpreting one's code cannot be decisive. These problems are in fact particularly prevalent for engineers designing and using new technologies." They surmise, then, that "the code is either currently incomplete, or it is complete but not sufficiently understood. This implies that the principles of morality, properly grasped and

${ }^{1}$ On the other hand, it could be argued that engineering also participates in activities that Tronto notes are "not care," such as the production of some kinds of goods and some forms of military "destruction." The engineering profession's contribution to consumer culture and the military industrial complex should be considered from a care ethics standpoint; however, this is beyond the scope of this paper. 
systematized, do not allow for rationally justified violation" [25, emphasis added]. In some situations, they imply, there seems to be a limit to the usefulness of moral reason.

In such cases, where rule utilitarianism under which the codes operate does not yield a consistent answer, Troxell and Troxell argue that engineers must consider the context of the situation. They suggest that "much of the difficulty given by moral situations, like engineering problems, rests on how one interprets the situational context - that is, the concrete features present in the situation," and they conclude that the codes alone are not sufficient to guide correct moral decisions. They suggest that engineers should also rely on "common sense" moral intuition when moral rules, or codes of ethics, don't provide clear guidance [25], since morality "is not some separate and distinct area of human activity - it is continuous with and inseparable from regular everyday practical reason, from how we look at and think through real situations as they arise in our lives." But they stop short of defining any sort of normative standard that engineers should follow.

I suggest that care ethics provides a solution to this problem. With its emphasis on situational context, if care ethics were to be incorporated into the codes of ethics, it would provide engineers with a normative standard that would account for context. Where would care ethics appear in the engineering codes of ethics? In addition to canons based on utilitarian principles, some canons are also based on virtues: honor, loyalty, responsibility, and integrity. Virtue ethics, Margaret McLaren argues, provides care ethics with a "standard of appropriateness" and a "normative framework." If we define care as a virtue, it can be incorporated into the codes as such.

Engster defines caring virtues as attentiveness, responsiveness, and respectfulness [19]. To these, Tronto adds competence and responsibility (although it should be noted that Tronto does not define these as virtues but as "elements" of caring practice [5]). While Engster describes these virtues in terms of one-to-one caring relationships [19], they can be usefully applied to the engineering profession in the codes of engineering ethics. These virtues are relevant to both the design choices engineers make and the way these choices are communicated to the public.

Attentiveness can be defined as the quality of "moral perception," or "noticing when another person is in need and responding appropriately" [19]. As Tronto notes, "If we are not attentive to the needs of others, then we cannot possibly address those needs" [5]. Engineers should be attentive to the needs of their users and the public in the design stage and recognize the moral dimension of their designs. Respect means to treat others "in ways that do not degrade them in their own eyes or the eyes of others, and makes use of the abilities they have" [19]. Engineers should communicate with the public in a way that respects the public's concerns and abilities, which may not be technical but are nonetheless valid. The Flint, Michigan water crisis is an example of the prolonged human suffering that can occur when engineers (and public officials) are not attentive to and respectful of local residents' concerns. 
Responsiveness "means engaging with others to discern the precise nature of their needs and monitoring their responses to our care" [19]. For Tronto, responsiveness requires a recognition that "care is concerned with conditions of vulnerability and inequality" [5]. Vulnerability

belies the myth that we are always autonomous, and potentially equal, citizens. To assume equality among humans leaves out and ignores important dimensions of human existence....Inequality gives rise to unequal relationships of authority, and to domination and subordination....The moral precept of responsiveness requires that we remain alert to the possibilities for abuse that arise with vulnerability [5].

It is crucial for engineers to recognize that they act and communicate with considerable authority in society, and that there is potential for abuse of this authority over more vulnerable people. Many engineering projects, from large public works projects such as the Dakota Access pipeline to mobile apps that track users' locations, affect people who are already vulnerable, and these projects may exacerbate their vulnerability. Care ethics acknowledges these power imbalances and demands responsiveness to them.

Responsibility and competence, for Tronto, involve a recognition that we have duties to others that go beyond basic legal or ethical obligations. Responsibility involves recognizing responsibilities to the community that go beyond contractual obligations [5]. Competence is already commonly found in many engineering codes of ethics. But Tronto adopts a more expansive definition of competence than engineers' obligation to work only in their areas of technical expertise. She warns against the tendency of workers in bureaucracies to "take care of," or pass off a problem "with no concern about outcome or end result" [5]. She notes that care ethics suggests a "more integrative approach to questions of ethics in general and in professions as well. Professional ethics," she continues, "should be about more than teaching professionals that it is wrong to lie, to cheat, and to steal. The guiding thought that ethical questions occur in a context should centrally inform professional ethics. From a perspective of care, we would not permit individuals to escape from responsibility for their incompetence by claiming to adhere to a code of professional ethics" [5]. This standard, which requires engineers to not blindly follow minimal moral rules but rather to consider the context of the situation, is ethically demanding.

\section{A more caring code of engineering ethics}

Given the relevance of the caring virtues outlined above to engineering design and communication, I suggest that they could be usefully incorporated into engineering codes of ethics. Taking the NSPE code of ethics as a general model [23], here I roughly sketch the types of changes that might be possible.

Under "Rules of Practice," I suggest the following changes:

2. Original: Engineers shall perform services only in the areas of their competence. 
Proposed: Add a sub-rule: "Engineers shall not hand over responsibility for a project to another engineer or manager without concern for its outcomes."

Under "Professional Obligations," I suggest the following changes:

1. Original: "Engineers shall be guided in all their relations by the highest standards of honesty and integrity."

Proposed: "Engineers shall be guided in all their relations by the highest standards of honesty, integrity, and respect for others."

1.e. Original: "Engineers shall not promote their own interest at the expense of the dignity and the integrity of the profession."

Proposed: "Engineers shall not promote their own interest at the expense of the dignity and the integrity of the profession or the needs of the public."

2. Original: "Engineers shall at all times strive to serve the public interest."

Proposed: Add a sub-rule: "Engineers shall make design choices that are attentive and responsive to public needs and interests."

3. Original: "Engineers shall avoid all conduct or practice that deceives the public." Proposed: Add a sub-rule: "Engineers shall communicate with the public in a responsive manner that respects their abilities and concerns."

On the whole, these changes emphasize the need for engineers to consider the other and encourage the engineer to consider the context of the situation. I acknowledge that any change to the codes of ethics is an arduous, slow process (to wit, the late and tepid "encouragement" for engineers to consider sustainability in their designs). Moreover, care ethics is a demanding moral standard, going beyond negative ethical duties and requiring active attention to particulars rather than passive adherence to standard moral principles. But, as John Stewart Mill admonished about the high standards of utilitarianism, "It is the business of ethics to tell us what are our duties" [26], not to make us comfortable. The benefits of care and empathy to the practice of engineering are widely acknowledged [27]. If the codes of ethics were updated to reflect current values of care in engineering, they would be more useful to practicing engineers and to engineering educators who use them in their classrooms.

\section{References}

[1] C. Gilligan, In a Different Voice. Boston: Harvard University Press, 1982.

[2] N. Noddings, Caring: A Feminine Approach to Ethics and Moral Education. Berkeley: University of California Press, 1984. 
[3] M. Pantazidou and I. Nair, "Ethic of Care: Guiding Principles for Engineering Teaching \& Practice,” Journal of Engineering Education, vol. , pp. 205-212, Apr. 1999

[4] L. S. Shulman, L. S., Foreword, in Educating Engineers: Designing for the Future of the Field, S. D. Sheppard, K. Macatangay, A. Colby, \& W. M. Sullivan, Eds. San Francisco, CA: Jossey-Bass, 2009.

[5] J. Tronto, Moral Boundaries: A Political Argument for an Ethic of Care. New York: Routledge, 1993.

[6] L. Kohlberg, "Moral stages and moralization: The cognitive-developmental approach," in Moral Development and Behavior: Theory, Research and Social Issues. T. Lickona, ed. New York: Holt, Rinehart and Winston, 1976.

[7] N. Haan, et al., "Family Moral Patterns" Child Development, vol. 47.7 pp. 1204-06, 1976.

[8] M. Brabeck, "Moral Judgment: Theory and Research on Differences between Males and Females," Developmental Review vol. 3, pp. 274-91, 1983.

[9] B. Puka, "The Liberation of Caring: A Different Voice for Gilligan's 'Different Voice,'" Hypatia vol. 55.1, pp. 58-82, 1990.

[10] C. Card, "Caring and Evil," Hypatia, vol. 5.1, pp. 101-8, 1990.

[11] V. Davion, “Autonomy, Integrity, and Care,” Social Theory and Practice, vol. 19.2, pp. 161-82, 1993.

[12] J. Rachels, The Elements of Moral Philosophy. San Francisco: McGraw-Hill, 1999.

[13] M. McLaren, "Feminist Ethics: Care as a Virtue," in Feminists Doing Ethics, P. DesAutels and J. Waugh, eds. Lanham, MD: Rowman \& Littlefield, 2001, pp. 101-118.

[14] L. Romkey, Attracting and Retaining Females in Engineering Programs: Using a Science, Technology, Society and the Environment (STSE) Approach, ASEE Annual Conference, 2007.

[15] A. Diekman, E. Brown, A. Johnston, and E. Clark, "Seeking Congruity Between Goals and Roles: A New Look at Why Women Opt Out of Science, Technology, Engineering, and Mathematics Careers," Psychological Science, vol. 21.8, pp. 1051-1057, 2010.

[16] N. Noddings, Starting at Home: Caring and Social Policy. Berkeley: University of CA Press, 2002. 
[17] L. Winner, “Do Artifacts Have Politics?” Daedalus, vol. 109.1. pp. 121-136, 1980.

[18] V. Held, Feminist Morality: Transforming Culture, Society, and Politics. Chicago: University of Chicago Press, 1993.

[19] D. Engster, The Heart of Justice: Care Ethics and Political Theory. Oxford: Oxford University Press, 2007.

[20] D. Riley, 2008. Engineering and Social Justice. Morgan and Claypool, 2008

[21] C. Baillie and G. Catalano. Engineering and Society: Working towards Social Justice (volumes 1 and 2). Morgan and Claypool, 2009.

[22] M. Martin and R. Schinzinger, Introduction to Engineering Ethics. 2nd ed. New York: McGraw Hill, 2010. p. 40.

[23] National Society of Professional Engineers, "Code of Ethics," 2007. Available: https:// www.nspe.org/resources/ethics/code-ethics.

[24] G. Troxell and W. Troxell, A Reflective Analysis on Professional Codes of Ethics, ASEE Annual Conference, 2017.

[25] S. K. A. Pfatteicher, "Depending on Character: ASCE Shapes Its First Code of Ethics," Journal of Professional Issues in Engineering Education and Practice, vol. 129.1. pp. 21-31, 2003.

[26] J.S. Mill, (1863), "Utilitarianism," in Ethical Theory: An Anthology. 2nd ed. R. ShaferLandau, ed. Oxford: Wiley, 2013.

[27] J. Hess, J. Strobel, R. Pan, and C. Wachter Morris, "Practicing Engineers' Perceptions of Empathy and Care: Derived Exploratory Factor Structure from a 37-Item Survey," ASEE Annual Conference, 